\title{
Analyzing Farmers' Network Structure Using ERGM: The Case of Ghana's Cocoa Farmers
}

\author{
Patience Pokuaa Gambrah ${ }^{1,2}$ \\ 1.School of Economics, Wuhan University of Technology, Wuhan 430070, China \\ 2.Faculty of Applied Sciences and Technology, Kumasi Technical University, Box 854, Kumasi, Ghana
}

\begin{abstract}
This study examines farmer's network formation and structure based on their location. Through the use of ERGM, we analyzed a dataset of 200 Ghanaian cocoa farmers obtained from four different villages by the use of their social network information sharing. We explored the characteristics of these networks in the various locations to see their similarities or otherwise, reliance with the stakeholders in order to assess knowledge exchange, with the assumption that improvements in these variables will help to achieve high performance. We found out that even though the farmers considered were in the same region and they grow the same kind of crops, with about $90 \%$ of them from the same ethnic group, their network structure were significantly different. It is therefore recommended that, stakeholders need to study the structure of farmers' network in their local locations before implementing important policies so as to get maximum productivity for their input. Thus, two networks may be for the same purpose, but might not have the same structure.
\end{abstract}

Keywords: exponential random graph models; farmers' network; cocoa sustainability; farmers' social network; cocoa farmers; structural characteristics; network formation

DOI: $10.7176 / \mathrm{JRDM} / 78-04$

Publication date:August $31^{\text {st }} 2021$

\section{Introduction}

Social Networks are illustrations of data which represents relationships. Whether the data obtained signifies social relations or cooperation's, the structure of the network reveal a decision-making route which depend on quite a number of factors. Network analysis deals with representing relationships defined by links among vertices (Caimo \& Gollini, 2020). When it comes to problems involving relationship study, exponential random graph models (Caimo \& Gollini, 2020, Strauss \& Ikeda, 1990) is seen as one of the new and imperative models used to define the structure of networks. ERGMs are stochastic models which see connection formation as a continuous time process (Broekel \& Hartog, 2011). It assumes the observed network at a point in time as a specific entity out of a set of several proposed networks having related features (Broekel \& Hartog, 2011). Thus permitting researchers to apply these models to specifically cross-sectional network data. ERGMs are to detect features which makes maximum the probability of the occurrence of a network with related features like the configuration of the observed network. Comparatively to other relational network analysis methods, an ERGM puts an emphases on the relations formed by structures of a relational network and its individual attributes (Jiao C., et al, 2017). ERGMs are actual useful models as they can combine different types of network statistic which were defined originally for networks by means of binary links showing the existence or otherwise of a link among nodes. Most network statistics which are mostly used are homophily, density, dyad-based statistics and triad-based statistics (Snijders et al., 2006).

Agriculture is considered as the most central part to African economic development (McArthur \& Sachs, 2019), but its sustainable development faces a lot of setbacks. Inadequate innovation capacity (Calestous Juma, 2011), low productivity (United Nations Development Program, 2012), deteriorating natural capitals and climate change (Jayne, 2010) have all made agricultural development not realise its full potential (United Nations Development Program, 2012). Also, in Ghana the agriculture sector is considered as facing sluggish proportion of scientific change (World Bank, 2017) as well as the sluggish development of other official and structural measures to improve development and growth. This means that diffusion of novel ideas in agricultural only would not be sufficient to cope with the above-mentioned challenges. Essential to our study is the conception that farming is structured within a social network of different actors tied to separate farmers but not an individual initiative (Oreszczynn et al., 2010). The ties can be characterized by one's vicinity, family or friendship through relations found among the farming value chain, or other relations such as with stakeholders. This means that, the linkages a farmer have could be seen as a particular kind of farm capital. They are able to be affected through different types of interactions within their networks, example is through ideas connections, which could add to their capabilities (Narayanam \& Narahari, 2011; Thuo et al., 2014).

Cocoa (Theobroma cacao) is a cash crop agricultural product, it is an essential crop because we obtain food, employment, income, resources for poverty reduction and industrial raw materials from it (Peprah, 2015). As of 2017/2018 cocoa crop year, majority of production (75.2\%) were contributed by Africa, Latin America (18.0\%) and Asia together with Oceania (6.9\%). Concerning cocoa beans which are dried as industrial raw material, 
Russia and Europe grind (37.2\%), Asia and Oceania (22.9\%), Africa (21.0\%) and America (19.0\%) (ICCO, $2019)$. In the case of cocoa consumption, Europe (46\%), Americas (32\%), Asia and Oceania (18\%) and Africa (4\%) (ICCO, 2017). Thus, the preservation of Theobroma cacao to guarantee unceasing production and supply is of global worry. Investigation of global cocoa economy between 2011/2012 and 2022/2023 established a firm drop in cocoa stock (ICCO, 2015). An exploration on the feared of reduction of cocoa revealed issues like low cocoa productivity, declining soil fertility, pests and diseases, outdated production systems, high cost of inputs, unavailability of inputs, poor farm management practices,( Peprah, K. 2019) effects of climate change and weather, inefficient marketing systems, low uptake of knowledge transfer, innovations, technology as well as advisory services, inadequate extension (ICCO, 2015) and incorrect ways of dissemination of these information and inputs.

Accordingly, there are numerous scientific approaches which have been established to control as well as manage these cocoa diseases and pests. Several sociocultural, physical, mechanical, chemical and biological methods are available for this same purpose (Thube et al, 2016). Research involving cocoa varieties endurable to fluctuating climate changes and devotion of study to strict cocoa quality standards are also ongoing. For years now, Cocoa has been the backbone of the economy of Ghana, making about $\$ 2$ billion in foreign exchange yearly and a key contributor to the Gross Domestic Product (GDP) (Wickramasuriya \& Dunwell, 2017). Now, the 'national treasure' might be causing a lot of worry for the West African country as a once-booming cocoa sector is facing the treat of reduction in productivity.

Current works have placed much focus on the cocoa plant through the deliberation of cocoa diseases, cocoa farmers' perception on environmental issues and many others (Gockowski et al, 2011; Afrane \& Ntiamoah, 2011; Codjoe et al, 2013). Also in the case farmers in the industry, much emphasis has been on their livelihood which is normally linked to cocoa profit (Peprah, 2015; Kolavalli \& Vigneri, 2011; Aithnard, 2014). The relations found in terms of cocoa natural environment concerning yield, purchasing and the numerous impact on poverty and disease and pet controls have also been researched (Vigneri, 2008; Kolavalli et al, 2012). There is still an existing literature gap regarding the consideration of how stakeholders implement these numerous solutions mentioned above. Which implies they have all the solutions but the way they implement these solutions are not helping in solving the problems. It also balls down to the people who are to implement these solutions, and they are the farmers. This means looking at the various structures of these farmers' network in their locations will be the best solution. This then move the problem from the listed problems above to networking. How stakeholders link with farmers to solve and implement these solutions. Established on the fact that existing study and additional communications has inadequately discourse farmers' authentic difficulties and context, we want to examine the network structure of farmers to better understand how farmers' network are form and the similarities/differences in these network to be able to use it in terms of performing any services for farmers, such that the various activities for farmers will be programed for them per their group structure not because they are all farmers. This is because although they are all farmers and produce the same crops, their way of doing things might be different, their believe and way of upbringing may affect the way they receive instructions or information from people outside of their community and this can be interpreted from the structure of their network in their local settings.

This study makes contribution to these discourse by establishing that sustainability of cocoa is to be seen further than the cocoa crop to embrace the network structure of the people involved in the implementation of the laid down solutions to the problems facing cocoa production. Those involve are first, producers of cocoa and then the cocoa workers like farm laborers, workers of Ghana Cocoa Board and also workers of public and private cocoa-buying firms. As far as the authors are concerned, there are no research work on farmers' networks that takes into accounts the structure of a network in two or more different locations to formulate a decision based on the network structure from these locations.

Our aim is to explain the features of a farmer social network as well as the structures of their relationship which has an impact on the network formation in the village. Research have revealed that properties like transitivity, reciprocal, expansiveness and popularity are found in relational networks (Borgatti et al., 2018; Schaefer et al., 2010). Even though there exist a huge number of empirical studies on the fundamental features of relational networks in their studies, just a few works applied ERGMs in their studies (Matous 2015; Nyantakyi-Frimpong et al 2019; Bodin et al. 2017). By contrast, relatively few studies have examined how farmers network are formed and the influence they have in their local settings. Farmers' networks allow institutions to get collective insight within a closed system of farmers for new ideas and innovation. Offering a unique opportunity to understand the social processes of network formation between farmers and their village and community at large. The other sections of this study is arranged as follows. The second Section present the basic theory of ERGMs. We then give the explanation of the method and the data sets used for evaluating the ERGM in Section 3. The fourth Section is a discussion on the models and results of our studies using Markov chain Monte Carlo maximum likelihood estimation and maximum pseudo-likelihood estimation after applying the ERGM and also the goodness of fit obtained. Finally, Section 5 gives the conclusions of our study, and 
providing some recommendations for farmers and stake holders.

\section{Exponential random graph model}

Many studies which uses exponential random graph modeling (ERGM) concentrates on building the theory of ERGM. Just a few works have practically applied ERGM in their study. For our study, we model farmers' relationship through the use of ERGM so as to understand the basic structures of these network so as to help in decision making process of stakeholders. In an ERGM we are likely to find two types of illustrative variables which are node and structural variables (Johannes Van Der Pol, 2019). The node variables comes from data types and can be age, size of a farm, gender and many others. Structural variables have indicators like degree distribution, triadic closure and subgraphs (Robins et al, 2007). ERGM are typically used for the modeling of relationship networks in the social sciences. Thus, any interpretable statistic can be used to model ERGM (Hunter et al, 2008).

Let the random matrix Y denote the adjacency matrix of a binary network and let y represent the support of $\mathrm{Y}$, then we may consider $\mathrm{Y}$ as the set of all attainable networks (Hunter et al, 2008). Usually, as in this study, we fix the number $\mathrm{n}$ of persons, so as to make $\mathrm{y}$ a subset of all $\mathrm{n} \times \mathrm{n}$ matrices which have entries that are all zero (0) or one (1) and which have all its diagonal entries zero, since the (i, j) entry shows an edge from $i$ to $j$. Compelling the diagonal to be zero shows that self-partnerships are forbidden. We considered the directed case in this study.

Table 1: Example of Some Explanatory Variables of ERGM (Robins et al 2007)

\begin{tabular}{|c|c|c|}
\hline $\mathbf{S} / \mathbf{N}$ & Variable & Description \\
\hline 1. & Triangle & The number of 3-cycles in the network. \\
\hline 2. & k-Star & $\begin{array}{l}\text { The number of nodes in the network with exactly } \mathrm{k} \text { adjacent edges with } \\
\text { unconnected end points. }\end{array}$ \\
\hline 3. & k-Degree & The number of nodes in the graph with degree $\mathrm{k}$ \\
\hline 4. & k-Cycle & The number of k-cycles in the network. \\
\hline 5. & $\begin{array}{l}\text { Geometrically } \\
\text { edgewise shared } \\
\text { partners }\end{array}$ & $\begin{array}{l}\text { The weighted sum of the number of edges in the network that have exactly i } \\
\text { shared partners weighted by the geometric sequence, }\left(1-e^{-\alpha}\right)^{i} \text { where } \alpha \text { is a } \\
\text { decay parameter }\end{array}$ \\
\hline 6. & $\begin{array}{l}\text { k-Edgewise shared } \\
\text { partners }\end{array}$ & The number of edges in the network that have exactly $\mathrm{k}$ shared partners \\
\hline 7. & $\begin{array}{l}\text { Geometrically } \\
\text { weighted degree }\end{array}$ & $\begin{array}{l}\text { The weighted sum of the counts of each degree, weighted by the geometric } \\
\text { sequence, }\left(1-e^{-\alpha}\right)^{i} \text { where } \alpha \text { is a decay parameter. }\end{array}$ \\
\hline 8. & Edge count & The number of edges in the graph \\
\hline 9. & Maximum geodesic & The length of the longest of the shortest paths between each pair of nodes. \\
\hline 10 & Isolates & The number of nodes in the network with no neighbors \\
\hline 11 & Node count & The number of nodes in the graph. \\
\hline
\end{tabular}

\section{Data and Methodology}

The study was conducted in the Bono region of Ghana. The selected villages are densely populated, and about $95 \%$ of the population are farmers. ERGMs was applied to a dataset of 200 Ghanaian cocoa farmers from 4 different communities using their agricultural information-sharing linkages. $68 \%$ of Ghanaian dwell in the rural areas, while agriculture gives $40 \%$ of export earnings, $54 \%$ of the GDP and $90 \%$ of the country's food needs (FAO Organization, 2018). About $40 \%$ of the population work in the agricultural sector, although this number has dropped from $45 \%$ in 2013, and the country's food imports has risen (World Bank, 2017). The country's agricultural system is characterized as small householder farmers with low inputs and outputs plots.

The data used for our study was collected in November 2019 in 4 different locations. The farmers' network information were prompted by the generation of a list of names by the question: "Name at least 2 people whom you seek advice from, outside of this household, who generally provide handy information concerning farming practices." In the surveyed villages of 200 households, of which 50 households were from each village. A faceto-face questionnaire was administered to all household heads in these 4 cocoa-producing farmer villages. The villages were randomly selected based on the fact that we can obtain over 50 participants who are cocoa farmers. Only cocoa-producing farmers were targeted to enable valid comparisons among farmers who grow similar crops.

There were a number of node attributes which we considered to possibly influence the structure of the network of which some are:

- $\quad$ Farmer experience: A continuous attribute signifying the years a farmer have been farming. Longer 
years of farming by a farmer may make him a source of enriched knowledge for other farmers to approach.

- $\quad$ Land size: The cultivated area by each farmer which shows his economical prominence. Well-to-do farmers might probably be dominant in the rural community agricultural network.

- $\quad$ Education: a binary attribute that represented whether or not a person had education so as to read and write basic instructions. That is if one is able to read and write he/she may be important in the network as many people who cannot read will fall on him for knowledge as to how to apply certain things.

The addition of these attributes helped in accounting for the exogenous effects whereas modeling the endogenous relations in these networks. The model description was carefully chosen based on goodness of fit tests.

\section{Results and Discussion}

\subsection{Network summary of all four locations}

We now explore the basic summary of all the networks of cocoa farmers' information-sharing networks. We precisely want to examine how these networks are as well as the extent to which they overlap in characteristics. The following are the attributes we considered; the ages of the farmers we approached for the data, their ages ranges from 21 years to over 60 years for all the 4 locations. Also the land size of the farmers interviewed ranges from 3 acres to 40 acres. There were also farmers who had other source of income apart from the cocoa farming such as trading, rearing of animals, planting of cashew, palm nut and planting of other food crops. Although all the farmers had other farms for food crops, these were basically those who take it as a source of income for them apart from their income from the cocoa. The number of years of farming experience were also considered which ranges from 2 years to 30 years for all the locations. We also considered whether or not a farmer is a Land owner or not. From table 2 we can see that from all the four locations, the land owners are more than the non-land owners. We also sort to know if a farmer was educated or not, and from all the locations those who were not educated were more than those that were educated. Again, where labour was gotten from was considered, it indicated that they were gotten from friends or they hire people to do it for them. Looking at the gender from table 2, it indicates the dominance of the males in all the four locations. Again when asked if a farmer was a member of any stakeholder group or farmer group they all answered in the negative. Again they also indicated that they receive information through face- to- face interactions. They also indicated that they receive information from the Agricultural extension officers and get their farm inputs from the Ministry of Food and Agriculture. All four locations also indicated that they are not able to get loans from banks to expand their farms or buy machines. They all indicated that they get support from government most of the time.

Table 2: network summary of all four locations

\begin{tabular}{|c|c|c|c|c|}
\hline Location & Location 1 & Location2 & Location3 & Location4 \\
\hline vertices & 50 & 50 & 50 & 50 \\
\hline total edges & 84 & 109 & 127 & 95 \\
\hline density & 0.06857143 & 0.08897959 & 0.1036735 & 0.07755102 \\
\hline Educated & $\begin{array}{ll}\text { NO } & \text { YES } \\
39 & 11 \\
\end{array}$ & $\begin{array}{lc}\text { NO } & \text { YES } \\
37 & 13 \\
\end{array}$ & $\begin{array}{lc}\text { NO } & \text { YES } \\
32 & 18 \\
\end{array}$ & $\begin{array}{ll}\text { NO } & \text { YES } \\
31 & 19 \\
\end{array}$ \\
\hline Gender & $\begin{array}{ll}\mathrm{F} & \mathrm{M} \\
15 & 35\end{array}$ & $\begin{array}{ll}\mathrm{F} & \mathrm{M} \\
14 & 36\end{array}$ & $\begin{array}{ll}\mathrm{F} & \mathrm{M} \\
8 & 42\end{array}$ & $\begin{array}{ll}\mathrm{F} & \mathrm{M} \\
7 & 43\end{array}$ \\
\hline Labor & $\begin{array}{l}\text { FRIENDS : } 26 \\
\text { HIRE: } 24\end{array}$ & $\begin{array}{l}\text { FRIENDS:28 } \\
\text { HIRE }: 22\end{array}$ & $\begin{array}{l}\text { FRIENDS:26 } \\
\text { HIRE:24 }\end{array}$ & $\begin{array}{l}\text { FRIENDS :29 } \\
\text { HIRE: } 21\end{array}$ \\
\hline Land Owner & $\begin{array}{ll}\text { NO } & \text { YES } \\
13 & 37\end{array}$ & $\begin{array}{ll}\text { NO } & \text { YES } \\
18 & 32\end{array}$ & $\begin{array}{ll}\text { NO } & \text { YES } \\
15 & 35\end{array}$ & $\begin{array}{ll}\text { NO } & \text { YES } \\
14 & 36\end{array}$ \\
\hline Mean & 3.32 & 4.32 & 5.04 & 3.8 \\
\hline $\mathrm{Sd}$ & 4.349243 & 3.413299 & 4.393687 & 3.374575 \\
\hline $\begin{array}{l}\text { Education(Mixing } \\
\text { matrix) }\end{array}$ & $\begin{array}{lr}\text { NO YES } \\
\text { NO 55 } 26 \\
\text { YES 26 } 3\end{array}$ & 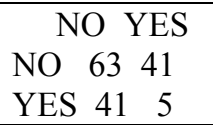 & \begin{tabular}{ccc}
\multicolumn{3}{c}{ NO YES } \\
NO & 40 & 65 \\
YES & 65 & 22
\end{tabular} & \begin{tabular}{lll}
\multicolumn{4}{c}{ NO YES } \\
NO & 18 & 54 \\
YES & 54 & 23
\end{tabular} \\
\hline $\begin{array}{l}\text { Land owner(Mixing } \\
\text { matrix) }\end{array}$ & \begin{tabular}{lll}
\multicolumn{3}{r}{ NO YES } \\
NO 3 & 28 \\
YES & 28 & 53
\end{tabular} & \begin{tabular}{lll}
\multicolumn{3}{c}{ NO YES } \\
NO $13 \quad 48$ \\
YES $48 \quad 48$
\end{tabular} & \begin{tabular}{lll}
\multicolumn{3}{c}{ NO YES } \\
NO & 6 & 49 \\
YES & 49 & 72
\end{tabular} & \begin{tabular}{l}
\multicolumn{3}{c}{ NO YES } \\
NO 136 \\
YES $36 \quad 58$
\end{tabular} \\
\hline $\begin{array}{l}\text { Labor(Mixing } \\
\text { matrix) }\end{array}$ & $\begin{array}{l}\text { FR HIRE } \\
\text { FR } 30 \quad 46 \\
\text { HIRE } 46 \quad 8\end{array}$ & $\begin{array}{l}\text { FR HIRE } \\
\text { FR } 30 \quad 53 \\
\text { HIRE } 53 \quad 26\end{array}$ & \begin{tabular}{l}
\multicolumn{3}{c}{ FR HIRE } \\
FR $32 \quad 67$ \\
HIRE67 $\quad 28$
\end{tabular} & 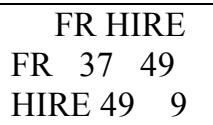 \\
\hline
\end{tabular}

The networks had an average degree of 3.32(4.35), 4.32( $\mathrm{sd}=3.41), 5.04(4.39)$ and 3.80( $\mathrm{sd}=3.37)$ so all the 4 locations were well linked thus connectivity of an average of 3.32, 4.32, 5.04 and 3.8. With 50 farmers and 84 , 109, 127 and 95 links between them, the above average may seem higher than one may expect. 
The network densities presented in Table 2 could be explain as the portion of relations created of all links which are likely to be formed. Thus, we found that farming related information moves within these locations very well and everyone is connected (Figure 1). There was no isolated farmer in the network which confirmed the high density in the network statistics. Again from figure 1, most of the individual farmers were well connected than others. Which may indicate some sort of homophile in the network. But the basic structures and statistics are different for all the four location, although they share some basic similarities. The network also show some potential clustering when we consider the mixing matrices (Table 2) of some of the attributes. From Goodreau et al (2008), a mixing matrix could be applied to scrutinize the number of linked dyads for every potential grouping categorical at levels for node attributes. For instance just how many dyads have both educated or how many dyads are there with one educated and the other not educated. In table 2 we found some evidence of clustering by education, land size and labour.

\section{Location 1 structure}

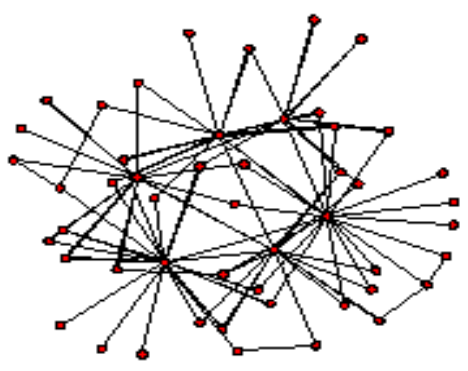

Location 3 structure

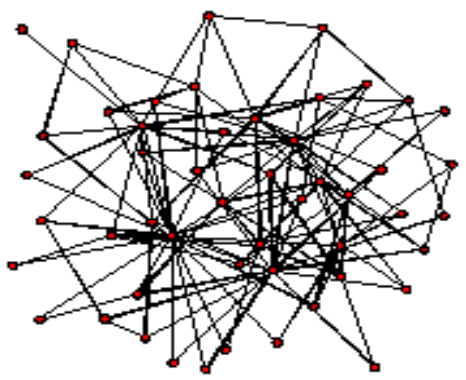

\section{Location 2 structure}

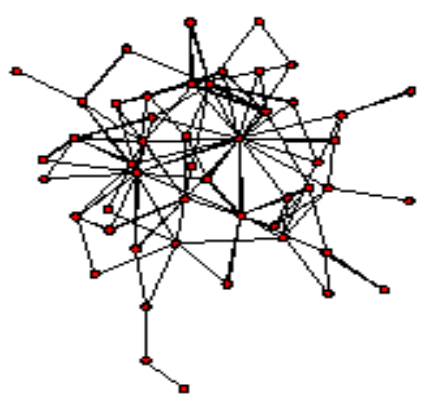

Location 4 structure

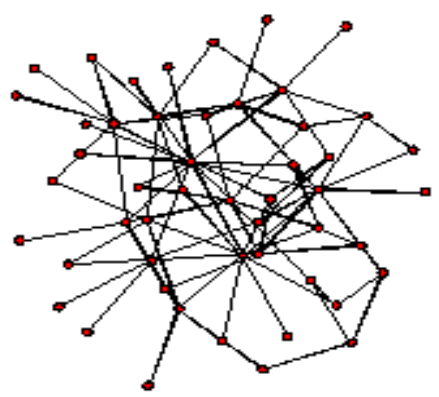

Figure 1: network structure of all four locations

\subsection{Degree distribution}

The degree distribution output, detailed analysis of degree, dyadwise shared partners (DSP) and edgewise shared partners (ESP) are also essential in understanding the underlying network structure. 

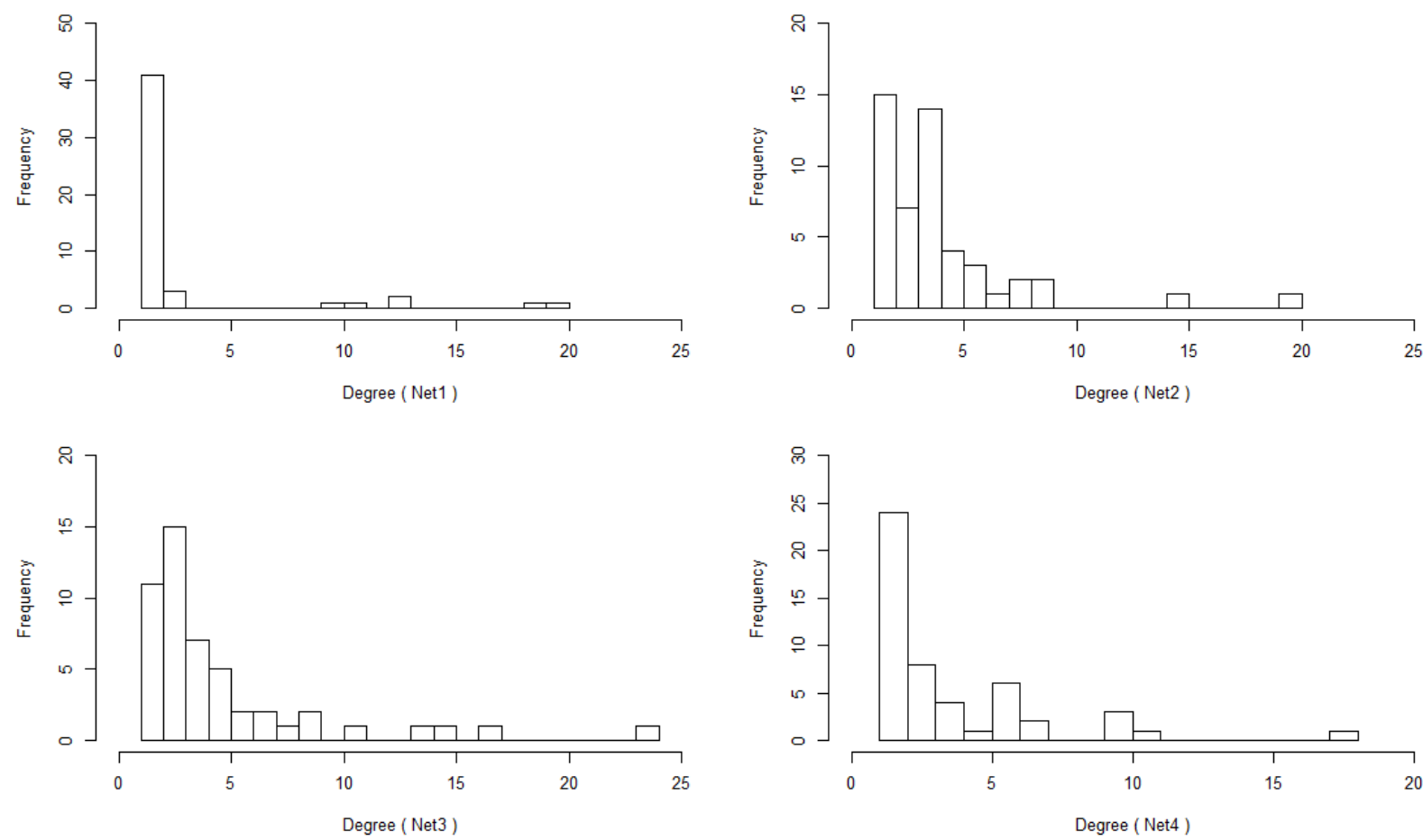

Figure 2: shared and degree partnerships plots in the observed Location 1, 2, 3 and 4 network

Thus, it could be seen that, the distribution of degree in the observed networks are not the same. Location 2 and 3 shows many low degree nodes followed by location 4 and then location 1 had the lowest number of low degree nodes. All the four locations too have a few high-degree nodes.
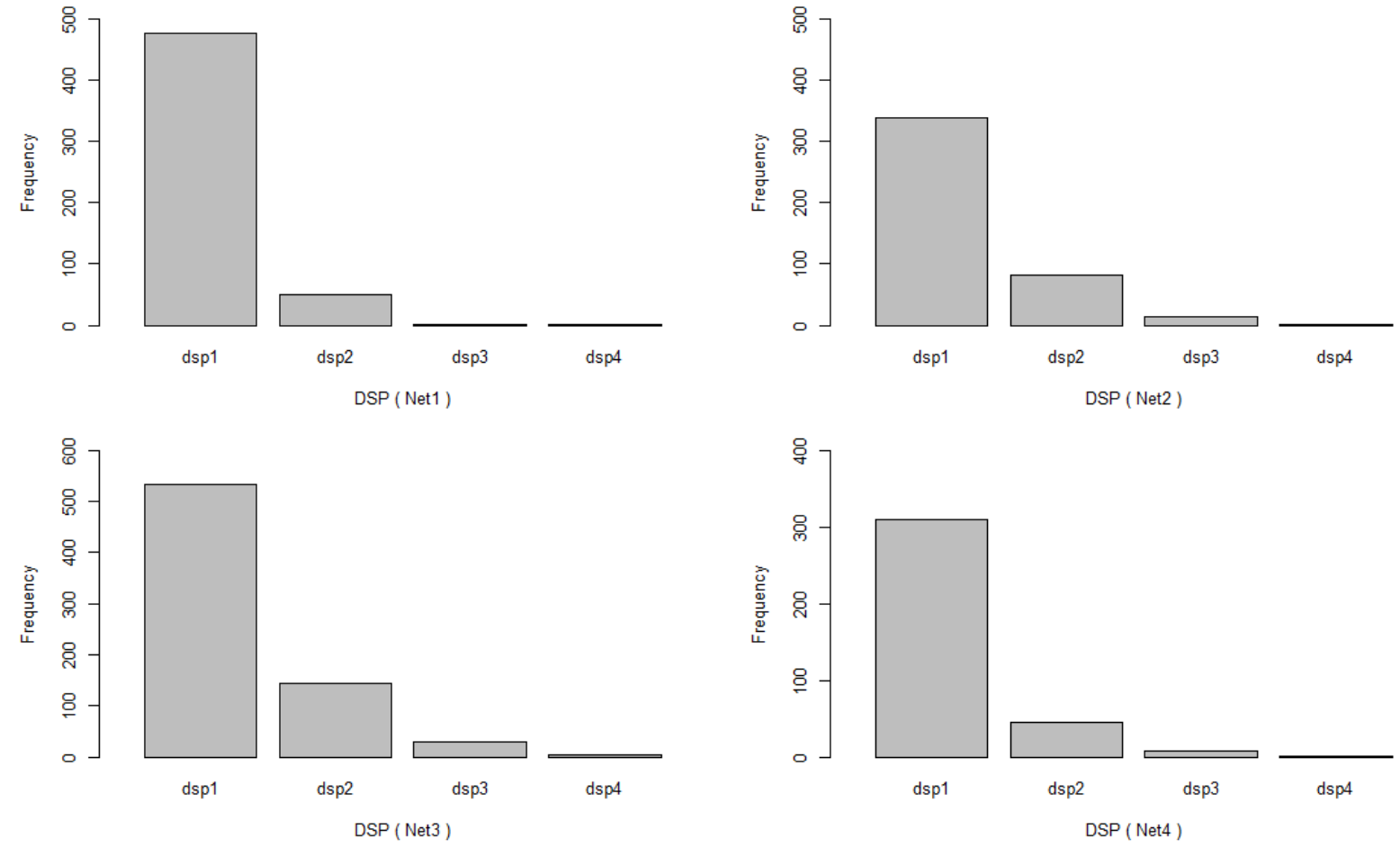

Figure 3: dyadwise shared partnerships plots in the observed Location 1, 2, 3 and 4 network

From figure 3, the DSP distributions also vary a bit in all the four locations, with location 2, 3 and 4 having more network members with multiple DSP than location1, this indicates a huge number of nodes with a little else in terms of shared partners and a single shared partner. 

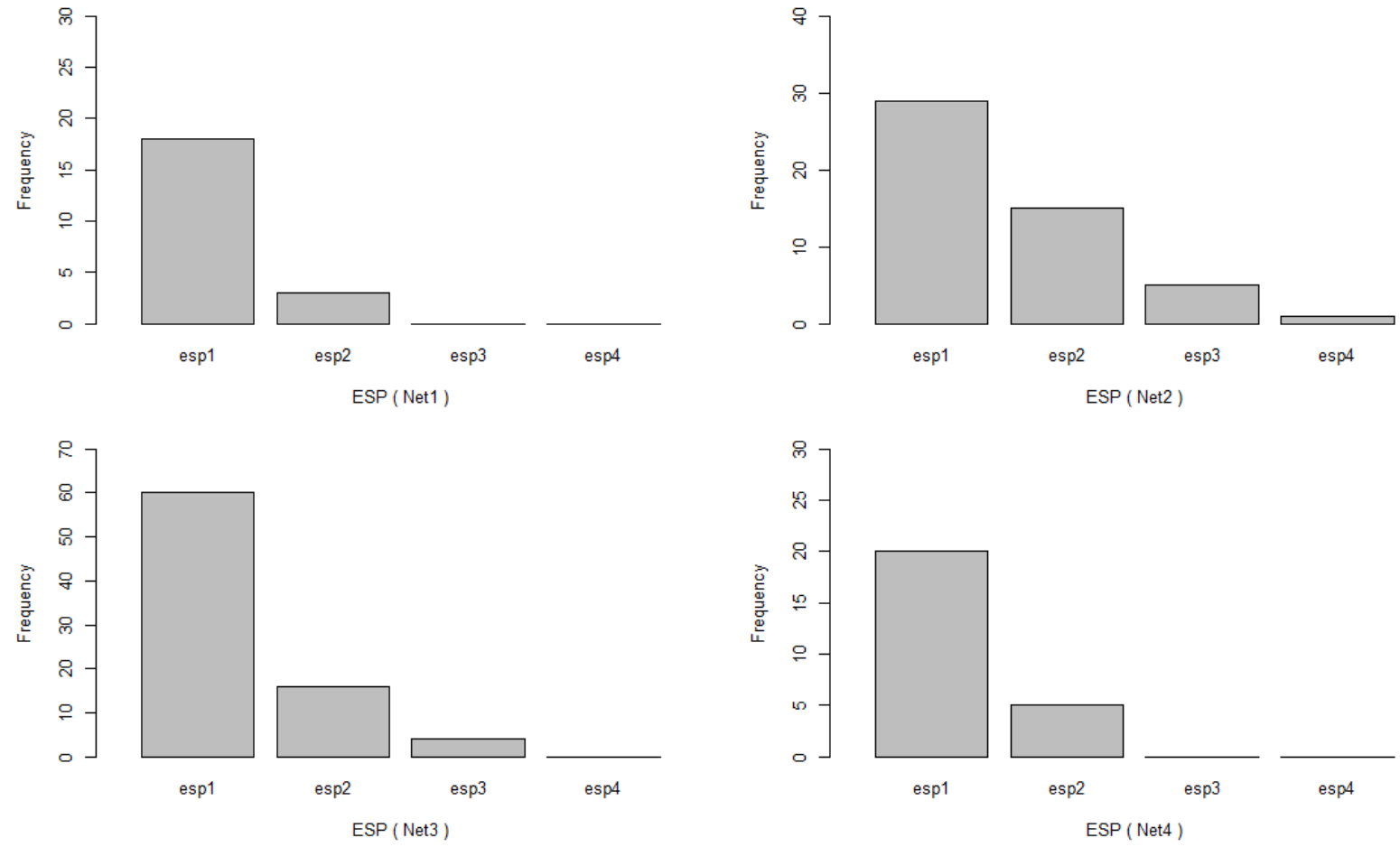

Figure 4: plots of edgewise shared partnerships in the observed Location 1, 2, 3 and 4 network

Edgewise shared partner distributions too vary in all the networks, with location 2 networks having more network members with multiple ESP, followed by lcation3 having more network members with 3 different ESP compared to location 1 and 4 network, which show only two shared partner.

\subsection{Model Building}

The null model

We now build models for the four networks to identify their characteristics to see how they differ in structure or otherwise. From all the four locations the edges were all significant in the model, which implies the model captures the edges very well, but we need to do more to see if the null model captured other network statistics like triangles. In all the locations, the coefficient for all the edge term is negative $(-2.648,-2.3988,-2.17475$ and2.5588 ), signifying that the density is less than $50 \%$.

Adding node attributes

We wish to improve our model so as to capture the basic network structure very well, so we will now add some node attributes which may make significant impact on the study. We consider years of farming experience and age of a farmer as this is likely to affect how ties are formed in the various locations. From all the four locations it was seen that the number of years of farming was not significant, but the age of a farmer was significant, although some had only one age group been significant, location 4 had 4 of its age group as significant. Which still prove the differences in the network structure of the various locations network. We still need to improve this model to include more statistic so as to capture more details of the various network.

\section{Adding interacting terms}

Whereas node attributes provide the features for each network, interactive terms for the node attributes gives description for the attributes of a dyad for both members (Morris et al., 2008). Some common interactive terms we wish to consider are those which might account for homophily (education, land owner and land size). This will also enrich our model for it to be able to capture other network statistics.

Testing a model including homophily terms

We still have to improve our model, so we went through modifying the homophily model to differential homophily for all the four location, and finally to Modifying the homophily model to keep only differential homophily for all the locations as that was a better representation of our networks. This saw an improvement in our model. All the model summary from the various location shown differences in the network structures and the basic attributes underlining its' formation. 


\subsection{Model fit}

We now examine our model to see how it fit the observed data for the various networks for the various locations. We then stimulated our model with the goodness of fit and made a comparison of the characteristics of our networks. These comparisons include information which are obs (number of nodes in our observed network), min(minimum number of nodes with the specified statistic across the stimulated networks), mean(average number with the value of the statistic across the stimulated networks), max(maximum number of the statistic with each value in the stimulated networks) and $\mathrm{MC}$ p-value(fraction of the stimulated values of the statistic that are at least as extreme as the observed value) which are all found in Table 4.

Table 3: Goodness-of-fit for model statistics

\begin{tabular}{|c|c|c|c|c|c|c|}
\hline & Parameter & obs & Min & Mean & Max & MC p-value \\
\hline \multirow{8}{*}{ Location1 } & Edges & 81 & 59 & 82.00 & 106 & 0.96 \\
\hline & Years of farming & 1717 & 1331 & 1742.39 & 2228 & 0.98 \\
\hline & Age $31-40$ & 25 & 13 & 24.94 & 42 & 1.00 \\
\hline & Age 51-60 & 26 & 14 & 25.78 & 40 & 0.98 \\
\hline & Age 61+ & 35 & 24 & 36.03 & 54 & 0.92 \\
\hline & Educated (YES) & 3 & 0 & 2.90 & 7 & 1.00 \\
\hline & Landowner (YES) & 52 & 39 & 51.68 & 73 & 0.94 \\
\hline & Land size & 9 & 3 & 9.33 & 16 & 1.00 \\
\hline \multirow[t]{7}{*}{ Location2 } & Edges & 102 & 79 & 100.97 & 121 & 0.98 \\
\hline & Years of farming & 2426 & 1843 & 2403.07 & 2972 & 0.98 \\
\hline & Age 41-50 & 59 & 38 & 58.42 & 77 & 0.96 \\
\hline & Age 51-60 & 51 & 35 & 50.32 & 64 & 1.00 \\
\hline & Educated (YES) & 5 & 0 & 5.30 & 14 & 1.00 \\
\hline & Landowner (YES) & 45 & 31 & 44.74 & 59 & 0.96 \\
\hline & Land size & 7 & 2 & 6.96 & 13 & 1.00 \\
\hline \multirow[t]{8}{*}{ Location3 } & Edges & 125 & 106 & 125.88 & 148 & 0.98 \\
\hline & Years of farming & 3505 & 2893 & 3523.12 & 4213 & 0.90 \\
\hline & Age $31-40$ & 55 & 36 & 54.69 & 73 & 1.00 \\
\hline & Age 51-60 & 17 & 10 & 17.22 & 27 & 1.00 \\
\hline & Age 61+ & 111 & 84 & 110.54 & 135 & 0.96 \\
\hline & Educated (YES) & 21 & 12 & 21.47 & 35 & 1.00 \\
\hline & Landowner(YES) & 71 & 53 & 71.65 & 89 & 0.96 \\
\hline & Land size & 14 & 7 & 14.22 & 24 & 1.00 \\
\hline \multirow[t]{9}{*}{ Location 4} & Edges & 88 & 63 & 88.97 & 110 & 0.92 \\
\hline & Years of farming & 2258 & 1475 & 2285.60 & 2863 & 0.86 \\
\hline & Age $31-40$ & 32 & 19 & 31.98 & 47 & 1.00 \\
\hline & Age $41-50$ & 68 & 48 & 69.10 & 95 & 0.94 \\
\hline & Age 51-60 & 2 & 0 & 1.88 & 6 & 1.00 \\
\hline & Age 61+ & 60 & 38 & 60.61 & 81 & 1.00 \\
\hline & Educated (YES) & 21 & 12 & 21.24 & 31 & 1.00 \\
\hline & Landowner (YES) & 53 & 36 & 53.31 & 76 & 1.00 \\
\hline & Land size & 16 & 7 & 16.42 & 27 & 1.00 \\
\hline
\end{tabular}

Goodness-of-fit simulations for the model

From the Goodness-of-fit tables for model statistics, all the MC p-value is larger than 0.05, which indicates that, the stimulated networks and the observed networks are similar on the characteristics of interest for all the four locations. This indicates that the model fit the data from all the four locations very well.

Table 4: Goodness-of-fit for degree

\begin{tabular}{|l|l|l|l|l|l|l|}
\hline & degree & obs & Min & Mean & Max & MC p-value \\
\hline Location1 & 0 & 0 & 0 & 3.73 & 11 & 0.02 \\
\hline & 1 & 11 & 3 & 8.47 & 16 & 0.52 \\
\hline & 2 & 30 & 4 & 10.00 & 17 & 0.00 \\
\hline & 3 & 3 & 3 & 8.59 & 15 & 0.04 \\
\hline & 4 & 0 & 1 & 6.40 & 16 & 0.00 \\
\hline & 5 & 0 & 0 & 4.40 & 10 & 0.02 \\
\hline & 6 & 0 & 0 & 3.00 & 9 & 0.10 \\
\hline & 7 & 0 & 0 & 2.25 & 6 & 0.20 \\
\hline
\end{tabular}




\begin{tabular}{|c|c|c|c|c|c|c|}
\hline & degree & obs & Min & Mean & Max & MC p-value \\
\hline & 8 & 0 & 0 & 1.48 & 5 & 0.48 \\
\hline & 9 & 1 & 0 & 0.87 & 4 & 1.00 \\
\hline & 10 & 0 & 0 & 0.43 & 3 & 1.00 \\
\hline & 11 & 1 & 0 & 0.22 & 2 & 0.38 \\
\hline & 12 & 1 & 0 & 0.08 & 2 & 0.14 \\
\hline & 13 & 1 & 0 & 0.06 & 1 & 0.12 \\
\hline & 14 & 0 & 0 & 0.02 & 1 & 1.00 \\
\hline & 18 & 1 & 0 & 0.00 & 0 & 0.00 \\
\hline & 19 & 1 & 0 & 0.00 & 0 & 0.00 \\
\hline \multirow[t]{16}{*}{ Location2 } & 0 & 0 & 0 & 1.33 & 4 & 0.46 \\
\hline & 1 & 5 & 0 & 4.56 & 11 & 0.92 \\
\hline & 2 & 11 & 1 & 7.74 & 15 & 0.36 \\
\hline & 3 & 8 & 3 & 8.99 & 16 & 0.88 \\
\hline & 4 & 14 & 2 & 8.53 & 16 & 0.04 \\
\hline & 5 & 2 & 1 & 6.78 & 16 & 0.12 \\
\hline & 6 & 4 & 0 & 4.78 & 10 & 0.98 \\
\hline & 7 & 2 & 0 & 3.31 & 7 & 0.64 \\
\hline & 8 & 1 & 0 & 2.08 & 6 & 0.72 \\
\hline & 9 & 1 & 0 & 1.08 & 3 & 1.00 \\
\hline & 10 & 0 & 0 & 0.47 & 2 & 1.00 \\
\hline & 11 & 0 & 0 & 0.26 & 2 & 1.00 \\
\hline & 12 & 0 & 0 & 0.05 & 2 & 1.00 \\
\hline & 13 & 1 & 0 & 0.03 & 2 & 0.04 \\
\hline & 15 & 0 & 0 & 0.01 & 1 & 1.00 \\
\hline & 19 & 1 & 0 & 0.00 & 0 & 0.00 \\
\hline \multirow[t]{18}{*}{ Location3 } & 0 & 0 & 0 & 0.36 & 2 & 1.00 \\
\hline & 1 & 1 & 0 & 1.66 & 5 & 0.98 \\
\hline & 2 & 11 & 0 & 4.23 & 11 & 0.02 \\
\hline & 3 & 14 & 3 & 6.98 & 11 & 0.00 \\
\hline & 4 & 7 & 4 & 8.92 & 14 & 0.60 \\
\hline & 5 & 5 & 2 & 8.22 & 18 & 0.30 \\
\hline & 6 & 2 & 2 & 7.33 & 16 & 0.06 \\
\hline & 7 & 2 & 1 & 5.46 & 13 & 0.22 \\
\hline & 8 & 1 & 0 & 3.05 & 9 & 0.30 \\
\hline & 9 & 2 & 0 & 1.89 & 6 & 1.00 \\
\hline & 10 & 0 & 0 & 1.06 & 5 & 0.66 \\
\hline & 11 & 1 & 0 & 0.51 & 3 & 0.78 \\
\hline & 12 & 0 & 0 & 0.21 & 1 & 1.00 \\
\hline & 13 & 0 & 0 & 0.10 & 1 & 1.00 \\
\hline & 14 & 1 & 0 & 0.02 & 1 & 0.04 \\
\hline & 15 & 1 & 0 & 0.00 & 0 & 0.00 \\
\hline & 17 & 1 & 0 & 0.00 & 0 & 0.00 \\
\hline & 23 & 1 & 0 & 0.00 & 0 & 0.00 \\
\hline \multirow[t]{12}{*}{ Location4 } & 0 & 0 & 0 & 2.26 & 5 & 0.12 \\
\hline & 1 & 13 & 2 & 6.08 & 13 & 0.02 \\
\hline & 2 & 11 & 2 & 9.22 & 19 & 0.70 \\
\hline & 3 & 10 & 3 & 10.28 & 17 & 1.00 \\
\hline & 4 & 3 & 2 & 8.69 & 15 & 0.08 \\
\hline & 5 & 1 & 1 & 6.12 & 12 & 0.04 \\
\hline & 6 & 7 & 0 & 3.40 & 8 & 0.06 \\
\hline & 7 & 0 & 0 & 1.90 & 8 & 0.34 \\
\hline & 8 & 1 & 0 & 0.65 & 4 & 0.90 \\
\hline & 9 & 1 & 0 & 0.34 & 2 & 0.58 \\
\hline & 10 & 1 & 0 & 0.08 & 2 & 0.14 \\
\hline & 11 & 1 & 0 & 0.12 & 2 & 0.22 \\
\hline
\end{tabular}




\begin{tabular}{|c|c|c|c|c|c|c|}
\hline & degree & obs & Min & Mean & Max & MC p-value \\
\hline & 12 & 0 & 0 & 0.09 & 1 & 1.00 \\
\hline & 13 & 0 & 0 & 0.14 & 1 & 1.00 \\
\hline & 14 & 1 & 0 & 0.15 & 1 & 0.30 \\
\hline & 15 & 0 & 0 & 0.15 & 1 & 1.00 \\
\hline & 16 & 0 & 0 & 0.09 & 1 & 1.00 \\
\hline & 17 & 0 & 0 & 0.08 & 1 & 1.00 \\
\hline & 18 & 0 & 0 & 0.05 & 1 & 1.00 \\
\hline & 19 & 0 & 0 & 0.05 & 1 & 1.00 \\
\hline & 20 & 0 & 0 & 0.02 & 1 & 1.00 \\
\hline & 21 & 0 & 0 & 0.02 & 1 & 1.00 \\
\hline & 22 & 0 & 0 & 0.01 & 1 & 1.00 \\
\hline
\end{tabular}

Form (Table 5) which is Goodness-of-fit for degree for all the locations, it could be seen that, there are differences in the MC p-values. While location1 recorded $7 \mathrm{MC} \mathrm{p}$-value which are less than 0.05 , location 2 recorded $3 \mathrm{MC} \mathrm{p}$-value which are less than 0.05, location 3recorded $6 \mathrm{MC}$ p-value which are less than 0.05 and location 4 recorded only $2 \mathrm{MC}$ p-value which are less than 0.05 . This shows that although from the model it indicates that they are all significant looking at the individual locations with specific statistic there some differences

Table 5: edgewise shared partner Goodness-of-fit

\begin{tabular}{|l|l|l|l|l|l|l|}
\hline & & obs & Min & Mean & Max & MC p-value \\
\hline Location1 & Esp0 & 60 & 37 & 56.33 & 76 & 0.68 \\
\hline & Esp1 & 18 & 0 & 19.82 & 40 & 0.78 \\
\hline & Esp2 & 3 & 0 & 4.59 & 14 & 0.94 \\
\hline & Esp3 & 0 & 0 & 1.00 & 6 & 1.00 \\
\hline & Esp4 & 0 & 0 & 0.02 & 4 & 1.00 \\
\hline & Esp5 & 0 & 0 & 0.02 & 1 & 1.00 \\
\hline Location2 & Esp0 & 52 & 49 & 67.13 & 91 & 0.04 \\
\hline & Esp1 & 29 & 9 & 26.95 & 46 & 0.72 \\
\hline & Esp2 & 15 & 0 & 5.70 & 14 & 0.00 \\
\hline & Esp3 & 5 & 0 & 1.09 & 8 & 0.08 \\
\hline & Esp4 & 1 & 0 & 0.09 & 2 & 0.16 \\
\hline & Esp5 & 0 & 0 & 0.01 & 1 & 1.00 \\
\hline Location3 & Esp0 & 42 & 50 & 73.40 & 97 & 0.00 \\
\hline & Esp1 & 60 & 19 & 38.76 & 63 & 0.02 \\
\hline & Esp2 & 16 & 1 & 11.36 & 28 & 0.56 \\
\hline & Esp3 & 4 & 0 & 2.00 & 9 & 0.42 \\
\hline & Esp4 & 0 & 0 & 0.34 & 7 & 1.00 \\
\hline & Esp5 & 1 & 0 & 0.02 & 1 & 0.04 \\
\hline & Esp6 & 1 & 0 & 0.00 & 0 & 0.00 \\
\hline & Esp8 & 1 & 0 & 0.00 & 0 & 0.00 \\
\hline & Esp0 & 63 & 42 & 58.58 & 73 & 0.46 \\
\hline & Esp1 & 20 & 6 & 23.24 & 41 & 0.66 \\
\hline & Esp2 & 5 & 0 & 5.57 & 16 & 0.94 \\
\hline & Esp3 & 0 & 0 & 1.21 & 7 & 0.88 \\
\hline & Esp4 & 0 & 0 & 0.28 & 3 & 1.00 \\
\hline & Esp5 & 0 & 0 & 0.07 & 1 & 1.00 \\
\hline & Esp6 & 0 & 0 & 0.02 & 1 & 1.00 \\
\hline & Location4 & 1 & \\
\hline & is & & 0 & 1 & \\
\hline
\end{tabular}

Table 6 which is edgewise shared partner Goodness-of-fit for all the locations, we notice that, there are differences in the MC p-values here too. While location 1 and 4 recorded no MC p-value less than 0.05 , location 2 recorded $2 \mathrm{MC}$ p-value which are less than 0.05 , and location 3 recorded $4 \mathrm{MC}$-value which are less than 0.05 . This shows that although the model significantly represented the observed networks very well, looking at the individual locations with specific statistic, we records some differences. 
Table 6: dyadwise shared partner Goodness-of-fit

\begin{tabular}{|c|c|c|c|c|c|c|}
\hline & & obs & Min & Mean & Max & MC p-value \\
\hline \multirow[t]{7}{*}{ Location1 } & dsp0 & 694 & 813 & 952.23 & 1063 & 0.00 \\
\hline & dsp1 & 475 & 140 & 227.10 & 322 & 0.00 \\
\hline & dsp2 & 51 & 13 & 38.83 & 78 & 0.38 \\
\hline & dsp3 & 2 & 0 & 5.81 & 18 & 0.58 \\
\hline & dsp4 & 1 & 0 & 0.95 & 7 & 0.96 \\
\hline & dsp5 & 1 & 0 & 0.06 & 1 & 0.12 \\
\hline & dsp6 & 1 & 0 & 0.02 & 1 & 0.04 \\
\hline \multirow[t]{6}{*}{ Location2 } & dsp0 & 788 & 735 & 867.14 & 1003 & 0.16 \\
\hline & dsp1 & 339 & 190 & 291.94 & 390 & 0.14 \\
\hline & dsp2 & 81 & 25 & 56.68 & 105 & 0.18 \\
\hline & dsp3 & 15 & 0 & 8.18 & 28 & 0.20 \\
\hline & dsp4 & 2 & 0 & 0.98 & 8 & 0.50 \\
\hline & dsp5 & 0 & 0 & 0.08 & 2 & 1.00 \\
\hline \multirow[t]{8}{*}{ Location3 } & dsp0 & 508 & 581 & 730.81 & 874 & 0.00 \\
\hline & dsp1 & 534 & 281 & 374.42 & 452 & 0.00 \\
\hline & dsp2 & 145 & 49 & 99.00 & 165 & 0.10 \\
\hline & dsp3 & 29 & 0 & 17.70 & 56 & 0.18 \\
\hline & dsp4 & 4 & 0 & 2.74 & 12 & 0.58 \\
\hline & dsp5 & 2 & 0 & 0.29 & 4 & 0.10 \\
\hline & dsp6 & 2 & 0 & 0.04 & 1 & 0.00 \\
\hline & dsp8 & 1 & 0 & 0.00 & 0 & 0.00 \\
\hline \multirow[t]{7}{*}{ Location4 } & dsp0 & 861 & 767 & 904.46 & 1045 & 0.40 \\
\hline & dsp1 & 309 & 166 & 268.80 & 387 & 0.34 \\
\hline & dsp2 & 46 & 7 & 44.06 & 89 & 0.98 \\
\hline & dsp3 & 8 & 0 & 6.54 & 21 & 0.72 \\
\hline & dsp4 & 1 & 0 & 0.97 & 9 & 1.00 \\
\hline & dsp5 & 0 & 0 & 0.15 & 2 & 1.00 \\
\hline & Dsp6 & 0 & 0 & 0.02 & 1 & 1.00 \\
\hline
\end{tabular}

Form table 7 which is dyadwise shared partner Goodness-of-fit for all the locations, we can observed that, there are differences in the $\mathrm{MC}$ p-values here also. With location2 and 4 recording no $\mathrm{MC}$ p-value less than 0.05 , location 1 recorded $3 \mathrm{MC} \mathrm{p}$-value which are less than 0.05 , and location 3 recorded $4 \mathrm{MC}$-value which are less than 0.05 .

Graphic goodness-of-fit for the final model

For one to make the interpretation that, the simulated networks has captured the characteristics of the observed network, the black lines must fall between the gray lines (Harris, 2014).
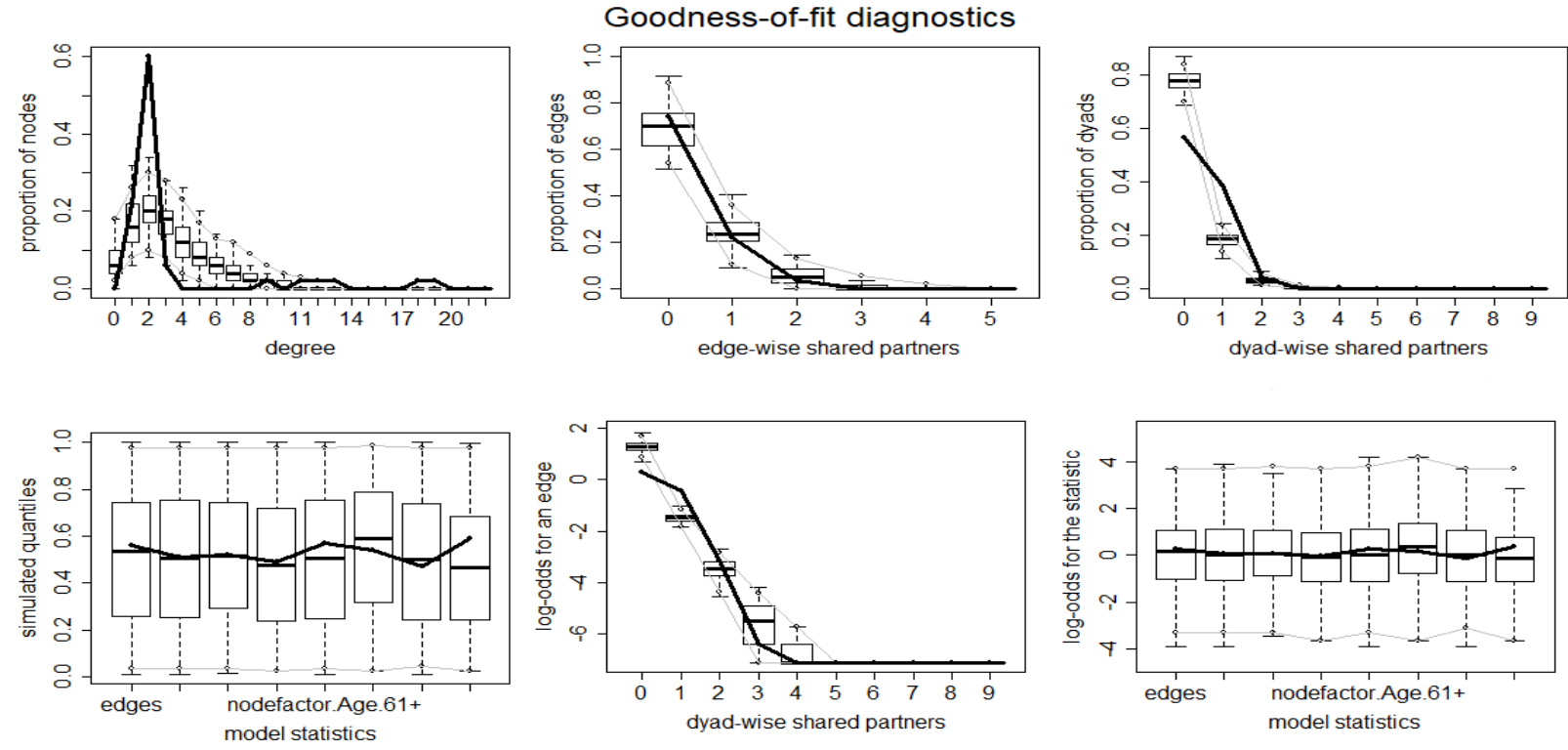

Figure 5:location1 
In location1 (Figure 5) 4 out of the 6 graph are capturing the characteristic of the network very well while the degree and DSP (at the top) are not.

\section{Goodness-of-fit diagnostics}
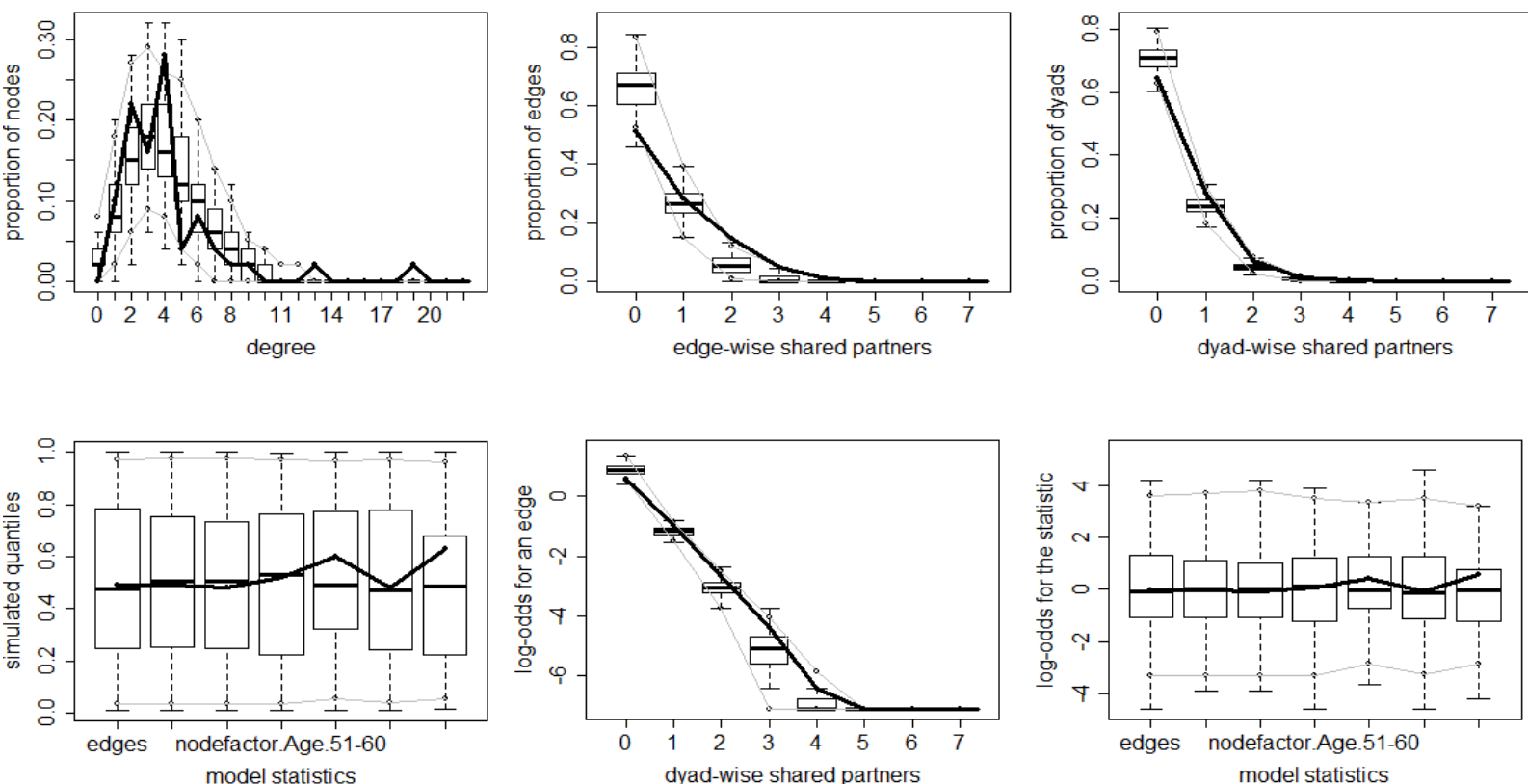

Figure 6:location2

Also, for location2 (Figure 6) all 6 graph are capturing the characteristic of the network very well.

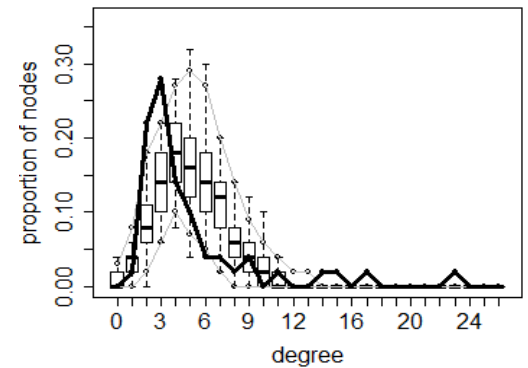

\section{Goodness-of-fit diagnostics}
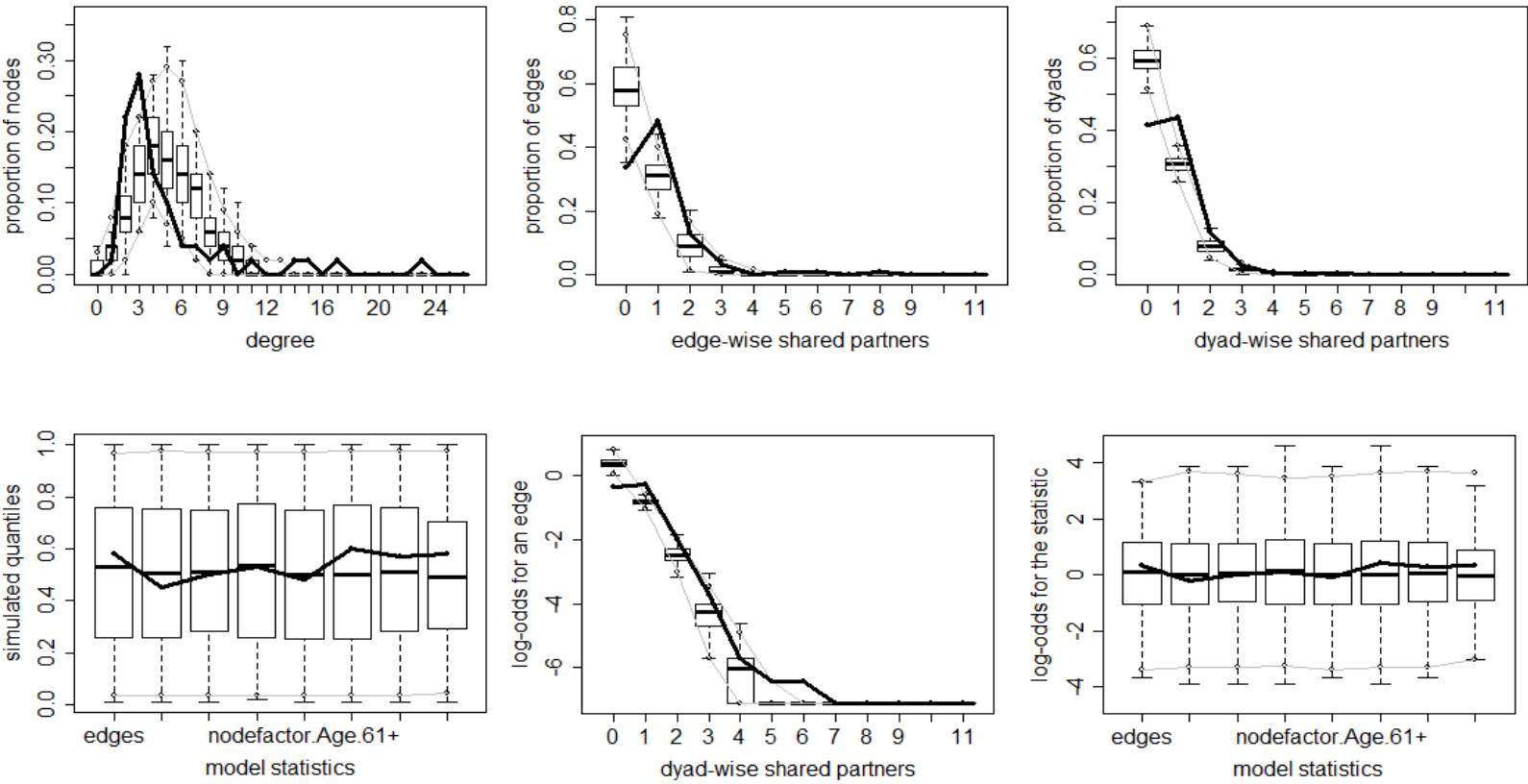

Figure 7:location3

In location3 (Figure 7) all the graphs are capturing the characteristic of the network very well. 


\section{Goodness-of-fit diagnostics}
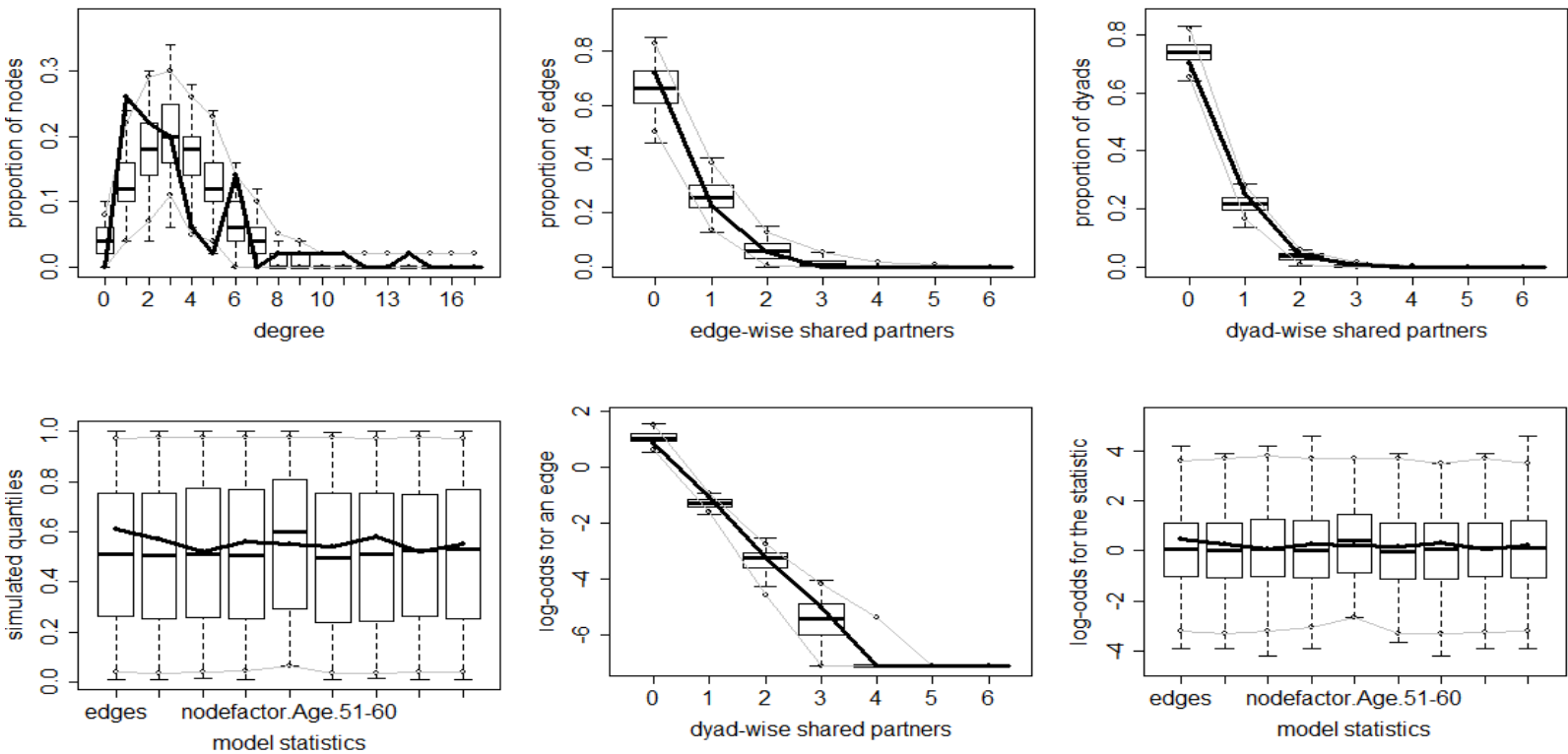

Figure 8:location4

Lastly, in location4 (Figure 8) all the graphs are capturing the characteristic of the network very well.

The results from this study have shown that there is a significant difference in all the locations' network structure. Therefore, these findings provide good support for our claim that the cocoa farmer network structure differ from location to location. All in all, we have realized that a cocoa farmer information flows relatively and widely unhindered in the study, even though years of farmer experience, age and social position (ie land ownership and education) do play a role for link formation, some locations were not influence by these attributes. Although the goodness- of- fit for the model statistics shown the statistics used in the model for all the locations to be significantly similar to the observed network, when we took the other measures there were some difference in the locations' network structure and formation. Also, we found confirmation for positive similarities with some attributes from all the locations, example, the age group that dominated were $60+$ which confirms the studies of (Naamwintome \& Bagson, 2013) that majority of our farmers' population is old, also the networks were well connected with no isolated nodes. Again all of the four locations had a density of less than $50 \%$. Also from the mixing matrix, the most connections were between hired and friends for all the locations and the land owners were linked with land owners more than with non-land owners for all locations. With these notwithstanding there were a lot of differences from one location to the other. Whenever we wish to rely on the current extension services to create information sharing plans, the diversity found within network characteristics and structures is to be taken into consideration.

\section{Conclusion}

In recent times, much prominence has been placed on how to make agriculture much more productive as a vital part in fighting the huge fear of cocoa extinction which will lead to the collapse of a lot of chocolate industries (Ploetz RC. 2007). Again developing countries like Ghana which depends much on this industry for most of its foreign exchange have a raising need for the high production of this commodity. To accomplish this, cocoa farming information can be spread to farmers in farmer groups by means of current agricultural extension systems. Yet, up till now little is known about the characteristics as well as the structure of agricultural information networks between farmers in their various locations/villages. Using network data from Ghana, we analyzed the structures of cocoa farmers' info networks among four locations and the features related to tie creation. Moreover, we found the features of key farmers who are drivers of information exchange in the networks, and also potentially homophile and clustering in some locations but the structures of these networks were totally different from one location to the other although they were all cocoa farmers.

Our results shown that comparably, cocoa farmers information networks are different. Thus a bit shocking, as these farmers in our sample were taken from the same region, where about $90 \%$ of them were from the same ethnic group and do a lot of things in common. This suggests that there is enough evidence for the need to train and sensitize group formations in these various locations for information exchange on farming-related topics, and thus make them much enriched in knowledge of the best farming practices and agriculture exchanges. As all the respondents in our sample received information outside their location through face-to-face interactions, the reporting may be hindered or delayed due to some unforeseen circumstances, it will therefore be very necessary 
for the group formation to be made as this will help when sending information and it can be done in other forms apart from the face-to-face interactions. Again it should be noted that no two farmers network are the same , therefore it is important to consider the network structure of a particular location before the introduction of anything in that area. Hence, putting farmers in groups is very necessary for the smooth and effective dissemination of agricultural information.

Our findings further suggest that farmers of certain age group in some locations are central and very important when it comes to diffusion of information in those networks and as such they might serve as appropriate persons to contact for extension programs, but this again boils down to knowing the structure of the network before you can tell which group of age should be the entry point. Also there were no isolated farmers in the network, which shows that the farmers have a strong connections, although some were only connected to one person.

Despite the fact that our results are promising, heterogeneity in network characteristics and structure should not be overlooked whenever we wish to rely on agricultural extension system to design programs for farmers. From our results, it could be seen that, stakeholders cannot take for granted the fact that farming related information is diffused normally among farmers planting the same crop. Therefore, providing a mixture of cocoa and agricultural trainings to diverse farmer groups via the extension services can be an appropriate means to accomplish this.

\section{References}

Afrane, G. \& Ntiamoah, A., (2011). Use of pesticides in the cocoa industry and their impact on the environment and the food chain. Pesticides in the modern world-risks and benefits. InTech, 51-68.

Aithnard, P-H. (2014). Ghana: Cocoa sector is facing new challenges. In: Middle Africa Briefing Note: Soft Commodities: Cocoa. Paris: Ecobank. 1-8

Bodin, Ö., Barnes, M.L., McAllister, R.R., Rocha, J.C. \& Guerrero, A.M. (2017). Social-Ecological Network Approaches in Interdisciplinary Research: A Response to Bohan et al. and Dee et al. Trends in Ecology \& Evolution, 32(8), 547-549.

Borgatti, S.P., Everett, M.G. \& Johnson, J.C. (2018). Analyzing social networks. Sage.

Broekel, T. \& Hartog, M. (2011). Explaining the structure of inter-organizational networks using exponential random graph models: does proximity matter. Papers in Evolutionary Geography, (11.07).

Caimo, A. \& Gollini, I. (2020). A multilayer exponential random graph modelling approach for weighted networks. Computational Statistics \& Data Analysis, 142, 106825.

Codjoe, F.N.Y., Ocansey, C.K., Boateng, D.O. \& Ofori, J. (2013). Climate change awareness and coping strategies of cocoa farmers in rural Ghana. Journal of Biology, Agriculture and Healthcare, 3(11), 19-29.

FAO: FAOSTAT Online Database (http://www.fao.org/faostat/2018)

Gockowski, J., Afari-Sefa, V., Sarpong, D.B., Osei-Asare, Y.B. \& Dziwornu, A.K. (2011). Increasing income of Ghanaian cocoa farmers: is introduction of fine flavour cocoa a viable alternative. Quarterly Journal of International Agriculture, 50(892-2016-65197), 175-200.

Goodreau, S. M., Handcock, M. S., Hunter, D. R., Butts, C. T., \& Morris, M. (2008). STATNET: Software tools for the representation, visualization, analysis and simulation of network data. Journal of Statistical Software. 24, 1-11. Special issue on STATNET.

Goodreau, S. M., Kitts, J., \& Morris, M. (2008b). Birds of a Feather, or Friend of a Friend? Using Exponential Random Graph Models to Investigate Adolescent Social Networks. Demography. 45. Forthcoming.

Naamwintome, B.A. and Bagson, E., 2013. Youth in agriculture: Prospects and challenges in the Sissala area of Ghana. Net Journal of Agricultural Science, 1(2), pp.60-68.

Harris, J. K. (2014). Quantitative Applications in the Social Sciences: An introduction to exponential random graph modeling. Thousand Oaks, CA: SAGE Publications

Hunter, D.R., Handcock, M.S., Butts, C.T., Goodreau, S.M., \& Morris, M. (2008). ergm: A package to fit, simulate and diagnose exponential-family models for networks. Journal of statistical software, 24(3), p.nihpa54860.

ICCO, (2015). Challenges and opportunities of the global cocoa and chocolate sector and position of the Russian market. In: Organization IC. Laurent Pipitone, Moscow: International Cocoa Organization. 1-27

ICCO, (2017). Quarterly Bulletin of Cocoa Statistics, Cocoa year 2016/17

ICCO, (2019). Quarterly Bulletin of Cocoa Statistics, Cocoa year 2018/19

Jayne, T. S., David, M., \& Elliot, M., (2010). Principal Challenges Confronting Smallholder Agriculture in SubSahran Africa. World Development. 38(10), 1384-1398

Jiao, C., Wang, T., Liu, J., Wu, H., Cui, F., \& Peng, X. (2017). Using Exponential Random Graph Models to Analyze the Character of Peer Relationship Networks and Their Effects on the Subjective Well-being of Adolescents. Frontiers in Psychology. 13, 1-11

Van Der Pol, J. (2019). Introduction to network modeling using exponential random graph models (ergm): 
theory and an application using R-project. Computational Economics, 54(3), 845-875.

Juma, C., (2011). The New Harvest: Agricultural Innovation in Africa. Oxford University Press

Kolavalli, S. and Vigneri, M. (2011). Cocoa in Ghana: Shaping the success of an economy. Yes, Africa can: success stories from a dynamic continent, 201-217.

Kolavalli, S., Vigneri, M., Maamah, H., \& Poku, J. (2012). The partially liberalized cocoa sector in Ghana: Producer price determination, quality control, and service provision. In: IFPRI Discussion Paper 01213. Washington, DC: IFPRI. 1-52

McArthur, J. W., \& Sachs, J. D. (2019). Agriculture, Aid, and Economic Growth in Africa. The World Bank Economic Review. 33(1), 1-20

Morris, M., Handcock, M. S., \& Hunter, D. R. (2008). Specification of Exponential-Family Random Graph Models: Terms and Computational Aspects. Journal of Statistical Software.

Narayanam, R., \& Narahari, Y., (2011). Topologies of strategically formed social networks based on a generic value function - Allocation rule model. Social Networks, 33, 56-69.

Nyantakyi-Frimpong, H., Matouš, P., \& Isaac, M. E. (2019). Smallholder farmers' social networks and resourceconserving agriculture in Ghana: a multicase comparison using exponential random graph models. Ecology and Society. 24(1).

Oreszczyn, S., Lane, A., \& Carr, S. (2010). The role of networks of practice and webs of influencers on farmers' engagement with and learning about agricultural innovations. J. Rural Stud., 26, 404-417

Peprah, K., (2019). Cocoa Plant, People and Profit in Ghana. In Theobroma Cacao-Deploying Science for Sustainability of Global Cocoa Economy. IntechOpen.

Peprah, K. (2015). Sustainability of cocoa farmers' livelihoods: A case study of Asunafo District, Ghana. Sustainable Production and Consumption. 4, 2-15

Ploetz, R. C. (2007). Cacao Diseases: Important Threats to Chocolate Production Worldwide. Symposium; eXtra. 972007, 1634-1639

Robins, G., Pattison, P., Kalish, Y., \& Lusher, D. (2007). An introduction to exponential random graph models for social networks. Social Networks. 29 (2), 173-191.

Robins, G., Snijders, T., Wang, P., Handcock, M., \& Pattison, P. (2007). Recent developments in exponential random graph $(\mathrm{p} *)$ models for social networks. Social Networks. 29, 192-215.

Schaefer, D. R., Light, J. M., Fabes, R. A., Hanish, L. D., \& Martin, C. L. (2010). Fundamental Principles of Network Formation among Preschool Children. Social Networks. 3, 61-71.

Snijders, T. A. B., Pattison, P. E., Robins, G. L., \& Handcock, M. S. (2006). New specifications for exponential random graph models. Sociological Methodology. 36, 99-153.

Strauss, D., \& Ikeda, M. (1990). Pseudolikelihood estimation for social networks. Journal of the American statistical association, 85(409), 204-212.

Thube, H. S., Saneera, E. K., \& Prathibha, P. S., (2016). Pests of cocoa and their management. The Cashew and Cocoa Journal. 4, 34-38

Thuo M. M., Martinez R. V., Lan W.-J., Liu X., Barber J., Atkinson M. B. J., et al. (2014). Fabrication of lowcost paper-based microfluidic devices by embossing or cut-and-stack methods. Chem. Mater. 26, 42304237.

UNDP (United Nations Development Program), (2012). Africa Human Development Report. Towards a Food Secure Future. Newyork, USA.1-190

Vigneri, M., (2008). Drivers of Change in Ghana's Cocoa Sector. Ghana Strategy Support Programme Background Paper 13; IFPRI2008.1-36

Wickramasuriya, A. M., \& Dunwell, J. M., (2017). Cocoa biotechnology: Current status and future prospects. Plant Biotechnology Journal. 16, pp.4-17

World Bank, (2017). Ghana: Agriculture Sector Policy Note, June. Washington DC: The World Bank, pp.1-63 